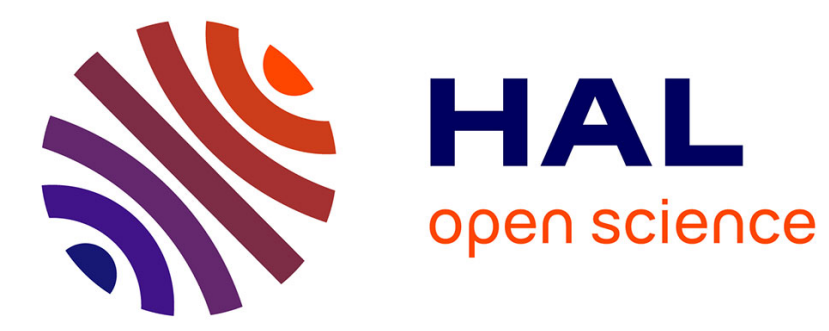

\title{
What moderates the influence of extremely negative ratings? The role of review and reviewer characteristics
} Raffaele Filieri, Elisabetta Raguseo, Claudio Vitari

\section{To cite this version:}

Raffaele Filieri, Elisabetta Raguseo, Claudio Vitari. What moderates the influence of extremely negative ratings? The role of review and reviewer characteristics. International Journal of Hospitality Management, 2018, 10.1016/j.ijhm.2018.07.013 . halshs-01923196

\section{HAL Id: halshs-01923196 \\ https://shs.hal.science/halshs-01923196}

Submitted on 17 Nov 2018

HAL is a multi-disciplinary open access archive for the deposit and dissemination of scientific research documents, whether they are published or not. The documents may come from teaching and research institutions in France or abroad, or from public or private research centers.
L'archive ouverte pluridisciplinaire HAL, est destinée au dépôt et à la diffusion de documents scientifiques de niveau recherche, publiés ou non, émanant des établissements d'enseignement et de recherche français ou étrangers, des laboratoires publics ou privés. 


\title{
What moderates the influence of extremely negative reviews? The role of review and reviewer characteristics
}

Authors: Raffaele Filieri, Elisabetta Raguseo, Claudio Vitari

\begin{abstract}
Online customer reviews (OCRs) are increasingly used by travelers to inform their purchase decisions. However, the vast amount of reviews available nowadays may increase travellers' effort in information processing. In order to facilitate traveller's decisions, social commerce organizations must help travellers rapidly identify the most helpful reviews to reduce their cognitive effort. Academic literature has often documented that negative reviews are judged as helpful by consumers. However, extremely negative reviews are not always perceived as such. This study is the first that unveils what factors moderate the influence of extremely negative reviews on review helpfulness. The study has adopted a sample of 7,455 online customer reviews of hotels to test hypotheses. Findings show that reviews with extremely negative ratings are more likely to be helpful when the review is long and easy to read and when the reviewer is an expert or discloses his identity (geographical origin).
\end{abstract}

Keywords online customer reviews; extremely negative ratings; review helpfulness; moderators; review length, review readability; reviewer expertise; hotels.

\section{Introduction}

A growing number of consumers trust and adopt online consumer reviews (OCRs) - a specific type of electronic word of mouth (eWOM) communication - to evaluate the quality 
and performance of the products and services they consider buying (Yoo et al. 2009; Sparks, Perkins, \& Buckley 2013; Filieri and McLeay 2014).

OCRs are particularly relevant for travel businesses as they influence consumers' alternatives evaluation and purchase intentions (Filieri and McLeay 2014; Filieri 2015; D.-H. Park, Lee, and Han 2007; Zhang and Watts 2008), product consideration and choice (Gupta and Harris 2010; J.-H. Huang and Chen 2006; Senecal and Nantel 2004; Vermeulen and Seegers 2009), and they impact on hotels’ sales (Ye et al. 2011), preferences (Viglia, Furlan, and Ladrón-deGuevara 2014) and financial performance (Phillips et al. 2017, Raguseo and Vitari 2017).

Although not all reviews are deemed to be helpful, helpful online reviews increase e-retailers’ sales (Ghose and Ipeirotis 2011). Hence, researchers in tourism have started investigating what makes an online review helpful (Fang et al. 2016; Kwok and Xie 2016; Liu and Park 2015; S. Park and Nicolau 2015).

Of particular interest of this study are extremely negative online ratings. With extreme negative ratings or reviews we refer to the lowest evaluation in a ranking scale to a product or service given by a reviewer, which is often indicated by an overall evaluation of one out of five stars in the review websites (e.g. TripAdvisor). In worth of mouth (WOM) (Herr, Kardes, and Kim 1991; Skowronski and Carlston 1989) scholars reveal that negative information are perceived as highly diagnostic (or helpful) by consumers and more influential on their decisions. While the understanding of the factors directly affecting helpfulness is consolidating, the moderating effects are still partially unexplored (Kwok and Xie 2016). Moreover, research in eWOM has found mixed results about the effect of extreme reviews on review helpfulness (Filieri 2016; S. Park and Nicolau 2015; Racherla and Friske 2012). For instance, Mudambi and Schuff (2010) found that product type moderates the influence of 
review extremity on the helpfulness of the review and that for experience goods (PC video game, music CD, MP3 player) online consumer reviews with extreme ratings (including extreme positive and negative reviews) are less helpful than reviews with moderate ratings. Park and Nicolau (2015) found that restaurant reviews with extreme ratings (both negative and positive) are voted as helpful by consumers and similar findings were obtained by other scholars (Forman, Ghose, and Wiesenfeld 2008; Korfiatis et al. 2012), while Filieri’s (2016) qualitative study show that some reviews with extreme ratings (both negative and positive) tend to be perceived as untrustworthy and thus unhelpful by travel consumers.

The analysis of moderating factors intervening in the relationship between extreme negative ratings and review helpfulness can help understand the reason of contrasting results in literature regarding the role of extreme reviews on consumer behavior, which are still understudied in eWOM research. We claim that not all extreme reviews are helpful and the reason for these mixed findings may be due to the fact that scholars did not measure separately the effect of extremely negative and extremely positive ratings on the helpfulness of the review in their studies. Extremely negative and extremely positive reviews are different as well as the motivations for posting them and their usage in a consumer decision making process (Yan and Wang 2018). Additionally, some factors other than product type (Sen and Lerman 2007; Mudambi and Schuff 2010) may moderate the relationship between extremely negative rating and review helpfulness. Thus, researching the variables that might moderate the influence of extremely negative ratings is needed.

Scholars have often used source and message characteristics to understand what makes reviews helpful (e.g. Pan and Zhang 2011; Racherla and Friske 2012; Park and Nicolau 2015; Liu and Park 2015; Kwok and Xie 2016). However, research on OCRs has not yet examined how different source and message dimensions of a review may influence the extent to which reviews with extremely negative ratings are voted as helpful by consumers. Thus, we 
conjecture that some factors may moderate the relationship between extremely negative ratings and review helpfulness, namely source factors such as reviewer identity disclosure (geographical origin of the reviewer), a dimension of source trustworthiness, and reviewer expertise, a dimension of source credibility (Hovland, Janis, and Kelley 1953), and message factors such as review readability and review length. We believe that these factors may moderate the influence that extreme negative ratings have on consumer evaluation of review helpfulness, such as when the reviewer is an expert or is perceived as trustworthy (namely he/ she discloses his real identity) or when the review is easy to read or when it is long enough to contain enough arguments to support an extreme evaluation.

Negative online reviews are particularly influential in determining a product's sales (Basuroy, Chatterjee, and Ravid 2003; Chevalier and Mayzlin 2006). From a managerial perspective, this study is useful for third-party e-retailers such as Booking.com or Tripadvisor.com to understand when extreme negative reviews will be more helpful to consumers. So by understanding to what extent extreme negative reviews are helpful, third-party e-retailers can filter results and show to users only the negative reviews that are most helpful based on the findings of this study. We have tested our framework using a sample of 7,455 online customer reviews of hotels published on TripAdvisor between 2013 and 2015.

\section{Review helpfulness}

eWOM refers to 'any positive or negative statement made by potential, actual or former consumers about a product or company, which is made available to a multitude of people and institutions via the Internet' (Hennig-Thurau et al. 2004, p. 39). eWOM is more influential and powerful than traditional WOM as it can reach a wider number of people more rapidly and on a global scale. Among different types of eWOM, online consumer reviews have 
probably received more attention in the academic literature. Online consumer reviews (OCR) can be defined as any positive, neutral, or negative feedback about a company’s product or service published in different types of online platforms (i.e. in: a company's website, a thirdparty retailer, an online community or forum, or a social media platform) by someone who claim to have used or purchased the reviewed product or service.

The integration of online reviews in the consumer purchase journey has created an entirely new industry including organizations offering the possibility to rate and review various products and services from universities to holiday services. As consumers are more willing to rate and review the product and service they buy, the number of reviews has grown to the point that consumers may find it difficult to retrieve the information they really need from consumer reviews. To overcome this problem, many third-party retailers such as TripAdvisor and Booking.com are increasingly providing signals to help consumers understand which reviews are more helpful to assess the quality and performance of the products and services that they sell. The helpful votes provided by travellers to the reviews hosted on third-party eretailers is one of those signals aimed at facilitating their purchase decisions. Consistently, review helpfulness refers to the number of 'helpful votes' received by a review from the users of a website who deemed the review to be helpful. Helpful online consumer reviews are particularly important for online businesses as they affect e-retailers’ sales (Ghose and Ipeirotis 2011), consumers’ purchase intentions (Filieri 2015), and travellers’ intentions to book a hotel room (Zhao et al. 2015).

The literature on the determinants of review helpfulness for travel and tourism services is rapidly developing. The explored determinants so far are: the review characteristics, in terms of content quality, length, complexity, readability, rating and extreme ratings (Fang et al. 2016; Liu and Park 2015; Park and Nicolau 2015; Kwok and Xie 2016), the reviewer background and characteristics, such as the reviewer’s gender (Kwok and Xie, 2016) 
expertise, reputation and identity disclosure (Liu and Park 2015; Fang et al. 2016; Park and Nicolau 2015; Racherla and Friske 2012), the hotel characteristics, such as the manager response (Kwok and Xie 2016).

\section{Negative eWOM}

One of the most discussed topics around online reviews is their valence, which is the evaluative tone of a review varying from very positive to very negative. Several studies have investigated the role of valence in eWOM; for instance negative reviews have been found to be particularly influential on business profitability as they affect product sales (Basuroy, Chatterjee, and Ravid 2003; Chevalier and Mayzlin 2006), and impact on attitude towards reviews (Sen and Lerman 2007). Park and Lee (2009) reveal that negative reviews influence readers more than positive ones, both for experience and search goods, while Racherla \& Friske (2012) reveal that negative reviews are perceived to be more useful than either extremely positive or moderate reviews.

Most of these studies rely on the belief that "bad is stronger than good" and that negative reviews influence consumers more than positive ones (Ahluwalia 2002; Sen and Lerman 2007). This assumption derives and it is justified in social psychology and referred to as negativity bias (Rozin and Royzman 2001). The negativity bias assume that negative events are more salient, potent, dominant in combinations, and generally efficacious than positive events (Rozin and Royzman 2001). Translated to information processing, negative information have more weight and attract individual's attention more than positive information (Fiske 1980).

Various studies have shown that negatively valenced information receives more weight than positive information (e.g., Hamilton and Huffman 1971; Wyer 1974). Negative and extreme 
cues are less frequent than positive and neutral and thus they tend to attract the attention of readers (Fiske 1980).

With regards to the helpfulness of negative reviews, it is suggested that negative information is more diagnostic or informative than positive or neutral information (Herr, Kardes, and Kim 1991; Skowronski and Carlston 1989). Negative information is perceived as helpful because it is less ambiguous and thus has higher impact on person impression (Birnbaum 1972; Hinkle 1976; Wyer 1974).

\section{Extremely negative ratings}

In eWOM research, Sen and Lerman (2007) found that negative reviews for hedonic products are less likely to be perceived as helpful compared to negative reviews of utilitarian products; Park and Lee (2009) reveal that negative OCRs influence readers more than positive ones, both for experience and search goods; Vermeulen and Seegers (2009) found that positive as well as negative reviews increase consumer awareness of hotels; Lee and Koo (2012) found that negative reviews have greater effect on credibility and information adoption than positive reviews; Racherla and Friske (2012) reveal that negative reviews are perceived to be more useful than either extremely positive or moderate reviews; Chua and Banerjee (2016) found that favorable reviews attract more helpful votes whereas unfavorable or mixed entries could remain largely ignored.

Previous studies on the antecedents of review helpfulness and in the context of review valence assessed the influence of extreme ratings (both positive and negative) without disentangling the effect of extremely positive or extremely negative ratings (Fang et al. 2016; Liu and Park 2015; S. Park and Nicolau 2015; Racherla and Friske 2012). Extreme negative, 1 star reviews, stem from consumer's dissatisfaction with a company, its products or services. 
Such reviews are less frequently posted compared to extremely positive, 5 star reviews (Chevalier and Mayzlin 2006; Hu, Zhang, and Pavlou 2009).

In this study we propose that extreme negative reviews have a positive relationship with review helpfulness as those reviews are less frequent and more attention-catching than other reviews (Fiske 1980). Thus, we propose that a review with a very low rating (1 star rating out of 5 stars) is helpful to consumers to assess the quality and performance of the products they plan buying. Therefore, we hypothesize the following:

H1: Extremely negative reviews will have a positive impact on review helpfulness.

\subsection{Factors moderating the influence of extremely negative reviews}

More recently, mixed findings have been obtained in studies investigating the role of negative reviews on review helpfulness suggesting that not all extreme reviews are considered as helpful (Filieri 2016). For example, Mudambi and Schuff (2010) found that reviews with extreme ratings (including extreme negative reviews) are less helpful than reviews with moderate ratings for experience goods; Cao et al. (2011) found that reviews with extreme opinions receive more 'helpful votes' than those with mixed or neutral opinions for different software programs; Park and Nicolau (2015) found that restaurant reviews with extreme ratings are voted as helpful by consumers; while Filieri’s (2016) qualitative study findings suggest that travelers perceive some extreme reviews (both positive and negative) as untrustworthy, thus unhelpful.

These mixed findings suggest that not all extreme negative ratings in reviews are perceived as helpful by consumers and that some factors might moderate the role of extreme negative ratings on review helpfulness. Based on previous research, in this study we consider the 
moderating role of source and message factors. In addition to review ratings, other determinants of review helpfulness investigated in the literature include review characteristics (e.g. content quality, length, complexity, readability) and reviewer background (e.g. reviewer's expertise, reviewer's identity disclosure) (Fang et al. 2016; Liu and Park 2015; S. Park and Nicolau 2015). Based on the above literature, we have assessed whether source (reviewer identity disclosure and reviewer expertise) and message content (review readability and review length) factors moderate the relationship between extreme negative rating and review helpfulness. Below we explain each in detail.

\subsubsection{Source factors}

\subsubsection{Reviewer identity disclosure (geographical origin)}

In eWOM communications the source is not physically present so identity cues such as the profile picture or the geographical origin of a reviewer can be particularly useful to reduce the uncertainty that arises from the lack of non-verbal communication cues that are generally used to infer the credibility of the source (Tidwell and Walther 2002). Providing identity cues can be important as consumers may use the reviewer's profile picture (real vs. default) to evaluate his trustworthiness (Filieri 2016). Forman, Ghose, and Wiesenfeld (2008) suggest that consumers use reviewer identity information online to supplement product information when using OCRs to help their decision making. They suggest that reviewers who provide identity-descriptive information are rated more positively, and that the prevalence of reviewer disclosure of identity information is associated with increases in subsequent online product sales. Similarly, Liu and Park (2015) found that reviewers’ identity disclosure has a significant impact on review helpfulness using a sample of 5,090 online reviews of restaurants in London and New York. 
However, other studies have found that a reviewer's identity information (i.e. real name and photo) has no direct significant positive effect on review helpfulness (Racherla and Friske 2012). In this study we focus on the geographical origin of the reviewer as one of the types of information most commonly provided by reviewers (Forman, Ghose, and Wiesenfeld 2008). The geographical origin of a reviewer can be important to make inferences about the helpfulness of its review and its trustworthiness (Filieri 2016). We argue that although the disclosure of geographical identity of a reviewer does not directly increase the helpfulness of a review, it may have an impact on the helpfulness of extremely negative reviews. Consistently, providing some identity cues (i.e. geographical origin) to a very negative review can increase the trustworthiness and consequently the potential helpfulness of an extremely negative review.

H2: Extremely negative reviews will be perceived as more helpful when the reviewer discloses his identity.

\subsubsection{Reviewer expertise}

Source credibility and trustworthiness are considered as fundamental predictors of a consumer's acceptance of a message in WOM (McGinnies and Ward 1980). Source expertise refers to the extent to which the source of a communication is perceived to be capable of making correct assertions by virtue of having relevant skills (Hovland, Janis, and Kelley 1953).

In websites publishing consumer reviews, it is often difficult to infer the expertise of a source (Chatterjee 2001) as the reviewer is often anonymous and consumers are required to use various cues to assess source expertise. For instance, in online settings consumers tend to 
assess the expertise of a reviewer based on the total number of reviews submitted by the reviewer (Filieri 2016; A. H. Huang et al. 2015; Weiss, Lurie, and MacInnis 2008).

Researches on the influence of source credibility on review helpfulness have produced mixed results. If from one side, Filieri (2015) found that source credibility has a weak influence on perceived information diagnosticity in a study on consumer reviews of accommodation, Racherla \& Friske (2012) using a dataset of 3.000 reviews from Yelp found that reviewer's expertise was negatively correlated with information usefulness for search, experience and credence products. Similarly, Liu and Park (2015) found that the reviewer’s experience in terms of number of submitted reviews has no impact on review helpfulness while Huang et al. (2015) found that reviewers who write more reviews do not necessarily write more helpful reviews.

In this study we argue that review expertise can moderate the influence that extremely negative reviews have on review helpfulness. If a source is perceived as an expert by virtue of his knowledge or expertise, his opinion, even when extreme, could be perceived as a more truthful representation of reality because of the 'expert' status of the source. Thus, we hypothesize the following:

H3: Extremely negative reviews will be perceived as more helpful when the reviewer is expert.

\subsection{Message characteristics}

\subsubsection{Review readability}

Review readability refers to how easily the text can be read and understood by consumers (Klare 1974; Smith and Taffler 1992). Readability is operationalized on 'how easy it is to 
read and comprehend a piece of text containing judgments related to the product being evaluated’ (Korfiatis, García-Bariocanal, and Sánchez-Alonso 2012, 205). A well-written review can help the reader to understand the social status, education level, and social hierarchy of the reviewer (Tausczik and Pennebaker 2010). Therefore, reviews with high readability can be considered as more reliable than reviews that are difficult to read (Fang et al. 2016). Previous research found that review readability influences sales (Ghose and Ipeirotis 2011) and review helpfulness (Fang et al. 2016; Korfiatis, García-Bariocanal, and Sánchez-Alonso 2012). Following this literature, we hypothesize that the readability of the review will reinforce the persuasiveness of an extremely negative review because the reader may think it comes from highly educated consumers. Thus, we hypothesize the following:

H4: Extremely negative reviews will be perceived as more helpful when the review is readable.

\subsubsection{Review length}

The number of words in a review indicates review length (A. H. Huang et al. 2015; Mudambi and Schuff 2010; Pan and Zhang 2011). According to marketing scholars the length of a review indicates the involvement of a reviewer in writing a review, and thus the expected credibility of the content (Chevalier and Mayzlin 2006; Pan and Zhang 2011). Researchers found that review length (word count) has a significant correlation with overall sales of books on Amazon (Chevalier and Mayzlin 2006) and has a positive impact on review helpfulness (Baek et al. 2012; Mudambi and Schuff 2010; Pan and Zhang 2011). According to Filieri (2016) longer reviews provide more information and more details about products and are also perceived as more trustworthy than short reviews. Following this literature, we argue that lengthy reviews can influence the impact of reviews with extremely negative ratings on 
review helpfulness. In fact, extreme reviews will be perceived more helpful when they are longer and thus likely to contain more information and arguments to provide support for the extreme evaluation compared to shorter ones. Especially in the domain of travel services this means conveying a sufficient amount of information with regards to all of the facets of a service being offered. Thus, we hypothesize as follows:

H5: Extremely negative reviews will be perceived as more helpful when the review is long.

\section{ADD FIGURE 1 HERE}

\section{Methodology}

\subsection{Data collection}

This study focused on online reviews of services. Due to their intangible and experiential nature of service, customers tend to search more and value higher reviews from previous customers in a service context, than in a product context (Papathanassis and Knolle 2011).

This research collected data from TripAdvisor using a sample of French hotels. We chose online customer reviews on TripAdvisor.com as our data for various reasons: (1) TripAdvisor.com is the most popular online travel website in the world (Miguéns, Baggio, and Costa 2008); (2) TripAdvisor offers a five-star rating system for posters, which made it easy for us to identify extremely negative reviews. The setting of French hotels was chosen because the French hotel industry is among the largest in Europe, and the second in terms of nights spends (Eurostat 2017), the hospitality industry has its considerable weight on the French economy, and because France is among the top five countries that will have the highest number of tourists booking on TripAdvisor in 2016 (TripAdvisor 2016).

A three-step approach was followed to collect the data for each hotel of the sample. First, we downloaded the list of hotels located in France from the IODS-Altares, a database that 
contains the economic and financial data of French companies. Second, from the extracted population, we randomly selected 220 hotels that have been reviewed on TripAdvisor, independently from their characteristics. The data collection process involved a stratified random selection of 220 French hotels from a population of 10,110 and was computed by considering a confidence level of 95 percent and a confidence interval of 7 percent. Third, for each hotel, we gathered OCRs in order to test hypotheses formulated in this study. In total, we used a sample of 7,455 OCRs on hotels written between 2013 and 2015. To collect the data on TripAdvisor for each hotel of the sample, we followed a two-step approach. First, we searched for the hotel page on TripAdvisor. Second, for each hotel, we recorded in a database the level of all the variables used in the models. We finally analysed data using STATA software version 11.

\subsection{Data operationalization}

The dependent variable in our model "Review Helpfulness" was measured using the logarithmic form of the number of helpful votes received by an online consumer review (Liu and Park 2015). We computed the logarithmic value given the skewness of the variable plot. The independent variable "Extreme negative ratings" is a dummy variable and equals to 1 if the review rating is 1,0 otherwise.

The moderator variables regarding the reviewer characteristics are: "Reviewer identity disclosure" and "Reviewer expertise". The first is a dummy variable equal to 1 in case the reviewer declares its own city, 0 otherwise (Forman, Ghose, and Wiesenfeld 2008). The second represents the helpful votes obtained by a reviewer, namely the number of reviews posted on TripAdvisor by a reviewer and assessed as helpful by other users (Ghose and Ipeirotis 2011). We computed the logarithmic value given the skewness of the variable plot. 
The moderator variables related to review message are: "Review readability" and "Review length”. The first represents the way the review is easy to read and it is represented through the computation of the Automated Readability Index (ARI) which is a metric to evaluate the readability of a language text. In order to calculate the ARI for a given review, we first calculated the total number of characters (excluding standard syntax such as hyphens and semicolons) and the total number of words (Korfiatis, García-Bariocanal, and SánchezAlonso 2012). ARI is calculated as follows:

$A R I=4.71 \times\left(\frac{\text { characters }}{\text { words }}\right)+0.5 x\left(\frac{\text { words }}{\text { sentence }}\right)-21.43$

In order to operationalize this variable, we finally computed the logarithmic value given the skewness of the variable plot.

"Review length” was measured as the number of words included in a consumer review (Liu and Park 2015). We computed the logarithmic value given the skewness of the variable plot.

Concerning the control variables, we included the dummy variables that refer to the identification numbers (ID) of hotels, each of which identifies all the OCRs that refer to one specific hotel, and the year when the review was posted. In this way we were able to control time, by including the variables related to the years, and contextual effects, by including the identification number of every hotel. In this way, we were able to combine, in the same model, variables that do not change over time with variables that change over time.

\subsection{Data analysis}


Following previous research (Mudambi and Schuff 2010), we used the Tobit regression model due to the specific feature of helpful votes (dependent variable) and the censored nature of the sample to analyse data. This decision was taken for two reasons. First, the dependent variable is bounded in the extremes since travellers may either vote the review helpful or unhelpful. In this way they are extreme in their assessment. Second, the Tobit model has the advantage of solving potential selection bias in case of this type of sample. TripAdvisor does not publicly provide any information about the number of people who read the online review; it only provides information about the number of total votes received by a review and their rating. If the probability of being part of a sample is correlated with an explanatory variable, the Ordinary Least Squares (OLS) and Generalized Least Squares (GLS) estimates can be biased (Kennedy 1994). Therefore, this study performs Tobit regression analysis by analysing the data and measuring the fit with the likelihood ratio and pseudo R-square value (Long 1997). The Tobit regression method was preferred also because it does not have the restriction that the OLS has regarding a zero value as missing value, while in this study the "zero value" of the dependent variable represents customers' perception of reviews that highlights that it is not used when it is read. In the models we included the interaction effects for testing the moderation between the extreme negative rating and the four moderating variables considered, by centring the variables involved. The resulting equation tested, including all the effects tested also isolated in different models, is the following:

OCR helpfulness $=\beta_{1}$ Extreme negative rating $+\beta_{2}$ Reviewer identity disclosure + $\beta_{3}$ Reviewer expertise $+\beta_{4}$ Review readability $+\beta_{5}$ Review length $+\beta_{6}$ Extreme negative rating $x$ Review identity disclosure $+\beta_{7}$ Extreme negative rating $x$ Reviewer expertise + $\beta_{8}$ Extreme negative rating $x$ Review readability $+\beta_{9}$ Extreme negative rating $x$ Review length $+\varepsilon$ 


\section{Results}

Table 2 shows the descriptive statistics of the sample. Specifically, the average number of reviews that are voted as helpful are $42.426 \%$ with an average review length of 79.7 words. The extreme negative reviews are 675 and the reviewers who have declared their city are $84.7 \%$.

\section{ADD TABLE 2 HERE}

Before running the Tobit regression models we tested for multicollinearity, which can be an issue in regression analysis. All the variables have acceptable values of VIF and tolerance levels and therefore the multicollinearity did not appear to be a problematic issue (see Table 3).

\section{ADD TABLE 3 HERE}

Table 4 shows the results of Tobit regression analysis. In Model 1 we included only the variable "extreme negative rating" in order to verify the effect of this variable on the dependent variable in isolation (before adding the moderators). In model 2, we included the four first-order variables that were used for computing the interaction effects with the extreme negative rating, and the four relative interaction effects. As shown by the $\beta$ coefficients, all the interaction effects are statistically significant and therefore reviewer identity disclosure, reviewer expertise, review readability and review length all play a positive moderating effect in the relationship between extreme review rating and review helpfulness.

\section{ADD TABLE 4 HERE}

To sum up, Figure 2 provides a graphical representation of the significant moderating effect found according to the high and low levels of the moderating variables. In order to define 
high and low values, we used a common method that is based on using values that are one standard deviation above and below the mean (Dawson 2014). Each graph contains two curves that represent the level of review helpfulness according to the review extreme rating, in case the moderating variable has a high or low value.
ADD
FIGURE
2
HERE

In order to provide an overview of the hypotheses supported and not, Table 5 shows a summary of the hypotheses validation.

ADD TABLE 5 HERE

\section{Discussion}

The current study attempts to understand the factors that contribute to reinforce (or reduce) the degree of helpfulness of extremely negative ratings. The study has investigated the moderating role of source factors, namely reviewer identity and expertise; and review message factors, namely review length and readability, in the relationship between extremely negative rating and review helpfulness. The results reveal strong support for the proposed model. We found that reviews with extremely negative ratings are likely to be voted as helpful by consumers. Extremely negative ratings are diagnostic because they tell consumers what really does not work in a product/service, which makes these reviews very helpful in consumer decision making. Extremely negative evaluations of a product/service/brand are rarer thus more attention-catching than other types of information (Fiske 1980). The study provides meaningful insights for researchers and industry professionals to consider in enhancing eWOM management. 


\subsection{Theoretical implications}

This study enhances the understanding of eWOM impact by introducing unique moderators of extremely negative ratings to review helpfulness. Traditionally in eWOM, information can be ranked according to the star rating provided to a review, which classifies reviews from extremely positive review to extremely negative reviews passing through negative, moderate and positive reviews. Previous eWOM research supports the idea that negative reviews are more helpful than either extremely positive or moderate reviews (Racherla and Friske 2012). However, recent publications highlight mixed findings about the influence that extreme ratings (considering both extremely positive and extremely negative) have on review helpfulness (Filieri 2016; Mudambi and Schuff 2010; S. Park and Nicolau 2015; Racherla and Friske 2012). In an effort to better explain these mixed findings, this study makes a contribution to the eWOM literature by specifically focusing on extremely negative ratings and investigates in what situations this type of reviews are more likely to be voted as helpful.

This study has found that the helpfulness of reviews with extremely negative ratings can increase or decrease depending on variables associated to the characteristics of the source and of the message, including respectively reviewer expertise, reviewer identity (source characteristics), and review length and review readability (message factors).

This study found that a short review with an overly negative rating is less likely to be considered helpful than a long review with the same rating sign. Previous studies found contrasting results regarding the role of review length. For instance, Kwok et al. (2016) found that review length is negatively related to review helpfulness and Filieri, Hofacker, Alguezaui (2018) found a non-significant relationship between lengthy reviews and perceived review helpfulness. From these results it appears that consumer tend to prefer reviews written in shorter or simpler sentences. However, other studies found that longer reviews are more 
likely to be voted as helpful (Baek, Ahn, and Choi 2012; Mudambi and Schuff 2010; Pan and Zhang 2011). This happens because long reviews are more likely to contain arguments or an in-depth discussion of the problems that somehow justifies the extremely negative evaluation of the reviewer. The presence of arguments may justify the reviewer's extremity in his feedback.

In this study we found that long reviews moderate the relationship between extremely negative rating and review helpfulness. Hotels are multifaceted experience services, therefore, a short one-star review can be perceived as a subjective and superficial assessment of a product. Lengthy reviews add more arguments that substantiate the reviewer's extreme evaluation, so that consumers perceive the review as more objective and rational, which may ultimately affects its persuasiveness. In summary, we can say that extreme negative ratings are more helpful when the review contains an in-depth evaluation of the product or service.

Review readability was another moderator considered in this study. We found that the easiness of read of the review message was also found to improve the helpfulness of review associated with extremely negative ratings. Previous studies found that review readability influences review helpfulness (Fang et al. 2016; Korfiatis, García-Bariocanal, and SánchezAlonso 2012). This study has proved that review readability moderates the relationship between extremely negative reviews and review helpfulness; thus reviews with extreme ratings that are easy to read will be perceived as more helpful than reviews than extreme negative reviews that are difficult to read.

We found that identity disclosure (i.e. geographical information) affect the degree of helpfulness of extremely negative rating. Our findings show that an extremely negative rating is more likely to be voted as helpful if it is written by a reviewer who discloses some information about his or her identity. Existing literature shows mixed results about the role of 
identity disclosure on review helpfulness. Liu and Park (2015) found that reviewers' identity disclosure has a significant impact on review helpfulness, while other studies found that reviewer’s identity disclosure does not directly affect review helpfulness (Baek, Ahn, and Choi 2012; Racherla and Friske 2012), this study found that identity disclosure (geographical origin of the reviewer) enhances the helpfulness of extremely negative ratings. This result may be explained by the fact that reviews with extreme rating are often perceived as less trustworthy compared to moderate reviews (Filieri 2016) and source identity cues may improve the trustworthiness of a reviewer expressing extreme evaluations.

Finally, reviewer expertise resulted to be the most important moderator in the relationship between extremely negative rating and review helpfulness. Previous studies found contrasting results regarding the role of reviewer expertise on review helpfulness (e.g., Liu and Park 2015; Racherla and Friske 2012). Past studies reveal that reviewers' expertise was either nonsignificant (A. H. Huang et al. 2015; Liu and Park 2015) or negatively correlated with review helpfulness (Racherla and Friske 2012). An expert reviewer is probably perceived as more trustworthy, and his/her extremely negative review will be more likely to be considered as helpful. The previous and current findings can be interpreted as follows: not all expert reviewers necessarily write helpful reviews; however extremely negative reviews written by expert reviewers are more likely to be considered as helpful.

Overall, it means that extreme negative reviews are more likely to be voted as helpful if they are long and easy to read and if they are posted by expert reviewers, who share some information about their identity (i.e. geographical origin). Thus, our study may contribute unveiling the conditions in which source trustworthiness and expertise are more relevant in the context of eWOM. Moreover, this study thus confirms the presence of a 'negativity bias' (Rozin and Royzman 2001) also for extremely negative evaluations supporting findings in eWOM (Korfiatis et al., 2012; Forman, Ghose, and Wiesenfeld 2008). 


\section{Managerial implications}

This study has implications for service providers in the hospitality industry and for social commerce operators such as TripAdvisor. First, managers of third-party websites could reward reviewers who post extremely negative ratings complying with the criteria of helpful extreme negative rating reviews found in this study. Short messages with suggestions on providing additional details could appear while reviewers write extremely negative reviews. Second, we found that extreme negative ratings are helpful to travelers. Thus, service providers (e.g. restaurant and hotel managers) that obtain an extreme negative rating should be aware that some of these extreme negative ratings (long, easy to read, written by expert reviewers who disclose their identity) are considered as particularly helpful by consumers and thus they may influence their decisions and consequently sales more than other types of extreme negative reviews (short and difficult to read reviews written by non-expert reviewers who do not disclose their identity). Thus, source expertise and identity disclosure as well as review readability and length contribute to amplify the relevance of extreme negative ratings. It is advisable that service providers identify these reviews as soon as they are published and promptly respond to them, without waiting for the other users to assess their helpfulness. It is known that management response can lower the impact of a review (Kwok and Xie 2016), thus this is much more important in the context of reviews with extremely negative ratings. A prompt, rational and convincing response by the service provider might attenuate the impact of an extremely negative review.

Racherla and Friske (2012) state that consumers prefer 'short, sweet and to the point' reviews, however this would not increase the helpfulness of extremely negative reviews, 
which to be considered as helpful must be long as long reviews contain several arguments that are generally used to rationally support an extremely negative evaluation.

Finally, this study has implications for social commerce providers, such as TripAdvisor, in that these findings can help the company's software engineers to develop an algorithm that is able to predict the helpfulness of extremely negative ratings based on the findings introduced in this study. This may help these organizations to sort first the most helpful extremely negative evaluations to consumers, by reducing information overload and improving users' satisfaction and experience.

\section{Future research and limitations}

This is one of the first studies that have investigated the moderating role of source and message factors in the relationship between extremely negative reviews and review helpfulness. Like many studies, ours is not exempt from limitations. First, our study considered exclusively linear effects and some, but not all, source and message factors as potentially moderating the relationship between extremely negative rating and review helpfulness. Some quadratic effects, worth further investigation, could be possible, for example, for review length. Future studies could consider different source and message factors or investigate the influence of product characteristics or quality (e.g. number of stars of a hotel). For instance, an extremely negative rating is more likely to have an impact on a high quality service (e.g. 4 or 5 stars hotel) rather than on an average one (e.g. 1 or 2 stars hotel). Additionally, future studies could measure the moderating role of consumers' previous experience with a product or service. For instance if a customer has previous positive experience with a hotel brand, he can discard an extremely negative review. In addition, the role of brand reputation could be assessed. Some brands are well known worldwide for 
providing excellent service quality standards in the context of the hotel industry, thus this reputation may mitigate the influence of a negative review. Moreover, future studies could assess the moderating effect of other identity disclosure information such as gender, real name or photo of the reviewer. Future studies could consider adopting surveys or experiments to measure the influence of perceptual factors of review helpfulness such as perceived brand reputation, and previous experience with a product or brand. Finally the exclusive consideration of variables changing over time would facilitate the test of a fixed effects model, detailing the effect of time and eventually discovering the existence of a temporal separation between the review time and the judgments on the helpfulness of the review.

\section{References}

Ahluwalia, Rohini. 2002. "How Prevalent Is the Negativity Effect in Consumer Environments?” Journal of Consumer Research 29 (2): 270-79. doi:10.1086/341576.

Baek, Hyunmi, JoongHo Ahn, and Youngseok Choi. 2012. "Helpfulness of Online Consumer Reviews: Readers' Objectives and Review Cues.” International Journal of Electronic Commerce 17 (2): 99-126. doi:10.2753/JEC1086-4415170204.

Basuroy, Suman, Subimal Chatterjee, and S. Abraham Ravid. 2003. "How Critical Are Critical Reviews? The Box Office Effects of Film Critics, Star Power, and Budgets.” Journal of Marketing 67 (4): 103-17. doi:10.1509/jmkg.67.4.103.18692.

Birnbaum, Michael H. 1972. "Morality Judgments: Tests of an Averaging Model.” Journal of Experimental Psychology 93 (1): 35.

Cao, Qing, Wenjing Duan, and Qiwei Gan. 2011. "Exploring Determinants of Voting for the 'Helpfulness' of Online User Reviews: A Text Mining Approach.” Decision Support Systems 50 (2): 511-21. doi:10.1016/j.dss.2010.11.009.

Casaló, Luis V., Carlos Flavián, Miguel Guinalíu, and Yuksel Ekinci. 2015. “Avoiding the Dark Side of Positive Online Consumer Reviews: Enhancing Reviews' Usefulness for High Risk-Averse Travelers.” Journal of Business Research 68 (9): 1829-35. 
Chatterjee, Patrali. 2001. “Online Reviews: Do Consumers Use Them?” SSRN Scholarly Paper ID 900158. Rochester, NY: Social Science Research Network. https://papers.ssrn.com/ abstract $=900158$.

Chevalier, Judith A, and Dina Mayzlin. 2006. "The Effect of Word of Mouth on Sales: Online Book Reviews.” Journal of Marketing Research 43 (3): 345-54.

Chua, Alton Y. K., and Snehasish Banerjee. 2016. "Helpfulness of User-Generated Reviews as a Function of Review Sentiment, Product Type and Information Quality.” Computers in Human Behavior 54 (January): 547-54. doi:10.1016/j.chb.2015.08.057.

Dawson, Jeremy F. 2014. "Moderation in Management Research: What, Why, When, and How.” Journal of Business and Psychology 29 (1): 1-19. doi:10.1007/s10869-013-9308-7.

Dellarocas, Chrysanthos, Xiaoquan Michael Zhang, and Neveen F. Awad. 2007. "Exploring the Value of Online Product Reviews in Forecasting Sales: The Case of Motion Pictures.” Journal of Interactive Marketing 21 (4): 23-45.

Eurostat. 2017. "Nights spent in tourist accommodation establishments” Eurostat. http://ec.europa.eu/eurostat/statistics-explained/index.php? title=File:Nights_spent_in_tourist_accommodation_establishments,_2016.png

Fang, Bin, Qiang Ye, Deniz Kucukusta, and Rob Law. 2016. “Analysis of the Perceived Value of Online Tourism Reviews: Influence of Readability and Reviewer Characteristics.” Tourism Management 52 (February): 498-506. doi:10.1016/j.tourman.2015.07.018.

Filieri, Raffaele, and Fraser McLeay. 2014. "E-WOM and Accommodation: An Analysis of the Factors That Influence Travelers' Adoption of Information from Online Reviews.” Journal of Travel Research 53 (1): 44-57. doi:10.1177/0047287513481274.

Filieri, Raffaele. 2015. "What Makes Online Reviews Helpful? A Diagnosticity-Adoption Framework to Explain Informational and Normative Influences in e-WOM.” Journal of Business Research 68 (6): 1261-70. doi:10.1016/j.jbusres.2014.11.006.

Filieri, Raffaele. 2016. “What Makes an Online Consumer Review Trustworthy?” Annals of Tourism Research 58 (May): 46-64. doi:10.1016/j.annals.2015.12.019.

Filieri, Raffaele, Charles F. Hofacker, and Salma Alguezaui. 2018. "What makes information in online consumer reviews diagnostic over time? The role of review relevancy, factuality, currency, source credibility and ranking score”. Computers in Human Behavior, 80: 122-131.

Fiske, Susan T. 1980. "Attention and weight in person perception: The impact of negative and extreme behaviour”. Journal of personality and Social Psychology, 38(6): 889.

Forman, Chris, Anindya Ghose, and Batia Wiesenfeld. 2008. "Examining the Relationship Between Reviews and Sales: The Role of Reviewer Identity Disclosure in Electronic Markets.” Information Systems Research 19 (3): 291-313. doi:10.1287/isre.1080.0193. 
Ghose, A., and P. G. Ipeirotis. 2011. "Estimating the Helpfulness and Economic Impact of Product Reviews: Mining Text and Reviewer Characteristics.” IEEE Transactions on Knowledge and Data Engineering 23 (10): 1498-1512. doi:10.1109/TKDE.2010.188.

Gupta, Pranjal, and Judy Harris. 2010. "How E-WOM Recommendations Influence Product Consideration and Quality of Choice: A Motivation to Process Information Perspective.” Journal of Business Research, Advances in Internet Consumer Behavior\& Marketing Strategy, 63 (9): 1041-49. doi:10.1016/j.jbusres.2009.01.015.

Hamilton, David L.; Huffman, Leroy J. 1971. Generality of impression-formation processes for evaluative and nonevaluative judgments. Journal of Personality and Social Psychology, 20(2), 200-207.

Hennig-Thurau, Thorsten, Kevin P. Gwinner, Gianfranco Walsh, and Dwayne D. Gremler. 2004. "Electronic Word-of-Mouth via Consumer-Opinion Platforms: What Motivates Consumers to Articulate Themselves on the Internet?” Journal of Interactive Marketing 18 (1): 38-52. doi:10.1002/dir.10073.

Herr, Paul M., Frank R. Kardes, and John Kim. 1991. "Effects of Word-of-Mouth and Product-Attribute Information on Persuasion: An Accessibility-Diagnosticity Perspective.” Journal of Consumer Research 17 (4): 454-62. doi:10.1086/208570.

Hinkle, Roscoe C. 1976. “Durkheim’s Evolutionary Conception of Social Change.” Sociological Quarterly 17 (3): 336-46. doi:10.1111/j.1533-8525.1976.tb00987.x.

Hovland, Carl I.; Janis, Irving L.; Kelley, Harold H. 1953. Communication and persuasion; psychological studies of opinion change. New Haven: Yale University Press.

Hu, Nan, Jie Zhang, and Paul A. Pavlou. 2009. "Overcoming the J-Shaped Distribution of Product Reviews.” Communications of the ACM 52 (10): 144-147. doi:10.1145/1562764.1562800.

Huang, Albert H., Kuanchin Chen, David C. Yen, and Trang P. Tran. 2015. “A Study of Factors That Contribute to Online Review Helpfulness.” Computers in Human Behavior 48 (July): 17-27. doi:10.1016/j.chb.2015.01.010.

Huang, Jen-Hung, and Yi-Fen Chen. 2006. "Herding in Online Product Choice.” Psychology and Marketing 23(5): 413-28. doi:10.1002/mar.20119.

Kennedy, P. 1994. A Guide to Econometrics. 3rd ed. Oxford, England: Blackwell Publishers Ltd.

Klare, George R. 1974. “Assessing Readability.” Reading Research Quarterly 10 (1): 62102. doi:10.2307/747086.

Korfiatis, Nikolaos, Elena García-Bariocanal, and Salvador Sánchez-Alonso. 2012.

"Evaluating Content Quality and Helpfulness of Online Product Reviews: The Interplay of Review Helpfulness vs. Review Content.” Electronic Commerce Research and Applications 11 (3): 205-17. doi:10.1016/j.elerap.2011.10.003. 
Kwok, Linchi, and Karen L. Xie. 2016. "Factors Contributing to the Helpfulness of Online Hotel Reviews: Does Manager Response Play a Role?” International Journal of Contemporary Hospitality Management 28 (10): 2156-77. doi:10.1108/IJCHM-03-20150107.

Lee, Kyung-Tag, and Dong-Mo Koo. 2012. "Effects of Attribute and Valence of E-WOM on Message Adoption: Moderating Roles of Subjective Knowledge and Regulatory Focus.” Computers in Human Behavior 28 (5): 1974-84. doi:10.1016/j.chb.2012.05.018.

Liu, Zhiwei, and Sangwon Park. 2015. "What Makes a Useful Online Review? Implication for Travel Product Websites.” Tourism Management 47 (April): 140-51. doi:10.1016/j.tourman.2014.09.020.

Long, J. Scott. 1997. Advanced quantitative techniques in the social sciences series, Vol. 7. Regression models for categorical and limited dependent variables. Thousand Oaks, CA, US. McGinnies, Elliott, and Charles D. Ward. 1980. "Better Liked than Right: Trustworthiness and Expertise as Factors in Credibility." Personality and Social Psychology Bulletin 6 (3): 467-72. doi:10.1177/014616728063023.

Miguéns, J., R. Baggio, and C. Costa. 2008. “Social Media and Tourism Destinations: TripAdvisor Case Study.” In Advances in Tourism Research, 6. Aveiro, Portugal.

Mudambi, Susan M., and David Schuff. 2010. "What Makes a Helpful Review? A Study of Customer Reviews on Amazon.Com.” MIS Quarterly 34 (1): 185-200.

Pan, Yue, and Jason Q. Zhang. 2011. "Born Unequal: A Study of the Helpfulness of UserGenerated Product Reviews.” Journal of Retailing 87 (4): 598-612. doi:10.1016/j.jretai.2011.05.002.

Papathanassis, Alexis, and Friederike Knolle. 2011. "Exploring the Adoption and Processing of Online Holiday Reviews: A Grounded Theory Approach.” Tourism Management 32 (2): 215-24. doi:10.1016/j.tourman.2009.12.005.

Park, Cheol, and Thae Min Lee. 2009. "Information Direction, Website Reputation and EWOM Effect: A Moderating Role of Product Type.” Journal of Business Research 62 (1): 61-67. doi:10.1016/j.jbusres.2007.11.017.

Park, Do-Hyung, Jumin Lee, and Ingoo Han. 2007. “The Effect of On-Line Consumer Reviews on Consumer Purchasing Intention: The Moderating Role of Involvement.” International Journal of Electronic Commerce 11 (4): 125-148.

Park, Sangwon, and Juan L. Nicolau. 2015. “Asymmetric Effects of Online Consumer Reviews.” Annals of Tourism Research 50 (January): 67-83. doi:10.1016/j.annals.2014.10.007.

Phillips, Paul, Stuart Barnes, Krystin Zigan, Roland Schegg. 2017. "Understanding the impact of online reviews on hotel performance: An empirical analysis”. Journal of Travel Research 56 (2): 235-249. 
Racherla, Pradeep, and Wesley Friske. 2012. "Perceived 'Usefulness' of Online Consumer Reviews: An Exploratory Investigation across Three Services Categories.” Electronic Commerce Research and Applications, Information Services in EC, 11 (6): 548-59. doi:10.1016/j.elerap.2012.06.003.

Raguseo, Elisabetta, and Claudio Vitari. 2017. "The Effect of Brand on the Impact of EWOM on Hotels’ Financial Performance.” International Journal of Electronic Commerce 21 (2): 249-69. doi:10.1080/10864415.2016.1234287.

Rozin, P., and Royzman, E. B. 2001. "Negativity bias, negativity dominance, and contagion”. Personality and social psychology review, 5 (4): 296-320.

Sen, Shahana, and Dawn Lerman. 2007. "Why Are You Telling Me This? An Examination into Negative Consumer Reviews on the Web.” Journal of Interactive Marketing 21 (4): 7694. doi:10.1002/dir.20090.

Senecal, Sylvain, and Jacques Nantel. 2004. "The Influence of Online Product Recommendations on Consumers’ Online Choices.” Journal of Retailing 80 (2): 159-69. doi:10.1016/j.jretai.2004.04.001.

Singh, Jyoti Prakash, Seda Irani, Nripendra P. Rana, Yogesh K. Dwivedi, Sunil Saumya, and Pradeep Kumar Roy. 2017. "Predicting the 'Helpfulness' of Online Consumer Reviews." Journal of Business Research 70 (January): 346-55. doi:10.1016/j.jbusres.2016.08.008.

Skowronski, John J., and Donal E. Carlston. 1989. "Negativity and Extremity Biases in Impression Formation: A Review of Explanations.” Psychological Bulletin 105 (1): 131-42.

Smith, Malcolm, and Richard Taffler. 1992. "Readability and Understandability: Different Measures of the Textual Complexity of Accounting Narrative.” Accounting, Auditing \& Accountability Journal 5 (4). doi:10.1108/09513579210019549.

Sparks, B. A., Helen H. Perkins, and Ralph Buckley. 2013. “Online travel reviews as persuasive communication: The effects of content type, source, and certification logos on consumer behavior”. Tourism Management 39: 1-9.

Tausczik, Yla R., and James W. Pennebaker. 2010. "The Psychological Meaning of Words: LIWC and Computerized Text Analysis Methods.” Journal of Language and Social Psychology 29 (1): 24-54. doi:10.1177/0261927X09351676.

Tidwell, Lisa Collins, and Joseph B. Walther. 2002. “Computer-Mediated Communication Effects on Disclosure, Impressions, and Interpersonal Evaluations: Getting to Know One Another a Bit at a Time.” Human Communication Research 28 (3): 317-48. doi:10.1111/j.1468-2958.2002.tb00811.x.

TriAdvisor. 2016. “TripBarometer.” TripAdvisor Insights. https://www.tripadvisor.com/TripAdvisorInsights/TripBarometer-en-US. 
Vermeulen, Ivar E., and Daphne Seegers. 2009. "Tried and Tested: The Impact of Online Hotel Reviews on Consumer Consideration.” Tourism Management 30 (1): 123-27. doi:10.1016/j.tourman.2008.04.008.

Weiss, Allen M, Nicholas H Lurie, and Deborah J MacInnis. 2008. "Listening to Strangers: Whose Responses Are Valuable, How Valuable Are They, and Why?” Journal of Marketing Research 45 (4): 425-36. doi:10.1509/jmkr.45.4.425.

Wyer, Robert S. 1974. "Changes in Meaning and Halo Effects in Personality Impression Formation.” Journal of Personality and Social Psychology 29 (6): 829-35.

Yan, Liping, \& Xiucun Wang. (2018). "Why posters contribute different content in their positive online reviews: A social information-processing perspective”. Computers in Human Behavior, 82: 199-216.

Yoo, Kyung-Hyan, Yoonjung Lee, Ulrike Gretzel, and Daniel R. Fesenmaier (2009). Trust in travel-related consumer generated media. Information and communication technologies in tourism 2009, 49-59.

Watts, Stephanie A., and Zhang, Wei. 2008. “Capitalizing on content: Information adoption in two online communities”. Journal of the Association for Information Systems, 9 (2): 3.

Zhao, Xinyuan (Roy), Liang Wang, Xiao Guo and Rob Law. 2015. “The influence of online reviews to online hotel booking intentions”, International Journal of Contemporary Hospitality Management, 27 (6): 1343-1346.

Zhu, Feng, and Xiaoquan (Michael) Zhang. 2010. "Impact of Online Consumer Reviews on Sales: The Moderating Role of Product and Consumer Characteristics.” Journal of Marketing 74 (2): 133-48. doi:10.1509/jmkg.74.2.133. 


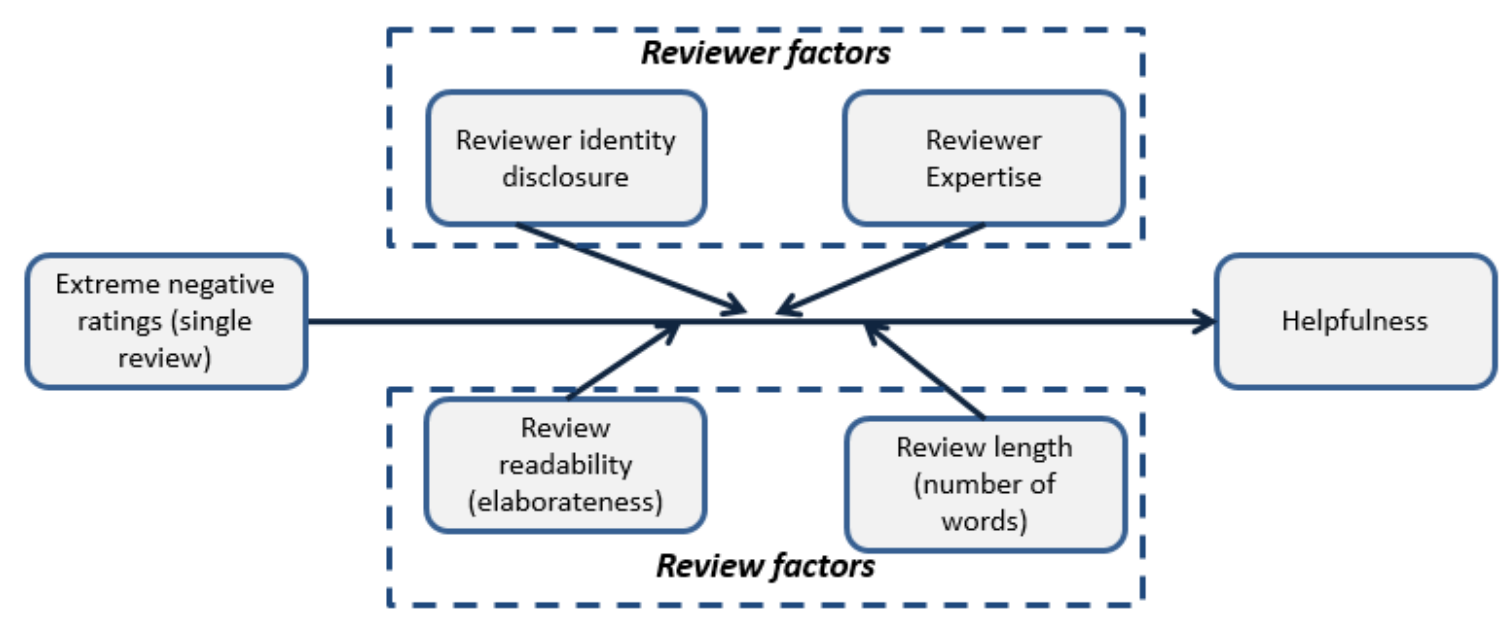

Figure 1. Framework of the study

\section{Table 1}

Variable operationalization.

\begin{tabular}{|c|c|c|c|}
\hline $\begin{array}{l}\text { Variable } \\
\text { type }\end{array}$ & $\begin{array}{l}\text { Variable } \\
\text { name }\end{array}$ & Definition & Operationalization \\
\hline $\begin{array}{l}\text { Dependen } \\
\text { t variable }\end{array}$ & Helpfulness & $\begin{array}{l}\text { The perceived value of a } \\
\text { given entry to inform purchase decisions } \\
\text { (Mudambi and Schuff } \\
\text { 2010) }\end{array}$ & $\begin{array}{l}\text { The number of helpful votes received by an } \\
\text { online review (Liu and Park 2015) }\end{array}$ \\
\hline $\begin{array}{l}\text { Independ } \\
\text { ent } \\
\text { variable }\end{array}$ & $\begin{array}{l}\text { Extreme } \\
\text { negative } \\
\text { ratings }\end{array}$ & $\begin{array}{l}\text { The lowest evaluation in a ranking scale to } \\
\text { a product or service given by a reviewer } \\
\text { (Filieri 2016) }\end{array}$ & $\begin{array}{l}\text { A dummy equal to } 1 \text { if the review rating is } 1,0 \\
\text { otherwise (new operationalization) }\end{array}$ \\
\hline \multirow[t]{4}{*}{$\begin{array}{l}\text { Moderato } \\
r \\
\text { variables }\end{array}$} & $\begin{array}{l}\text { Reviewer } \\
\text { identity } \\
\text { disclosure }\end{array}$ & $\begin{array}{l}\text { The online provision of } \\
\text { information about message } \\
\text { identity (Liu and Parkek 2015) }\end{array}$ & $\begin{array}{l}\text { A dummy variable equal to } 1 \text { in case the } \\
\text { reviewer declares its own city, } 0 \text { otherwise } \\
\text { (Forman, Ghose, and Wiesenfeld } 2008 \text { ) }\end{array}$ \\
\hline & $\begin{array}{l}\text { Reviewer } \\
\text { expertise }\end{array}$ & $\begin{array}{l}\text { The extent to which the reviewer is } \\
\text { perceived to be capable of making correct } \\
\text { assertions by virtue of having relevant } \\
\text { skills (Hovland, Janis, and Kelley 1953) }\end{array}$ & $\begin{array}{l}\text { The number of online reviews written by a } \\
\text { reviewer (Weiss, Lurie, and MacInnis 2008) }\end{array}$ \\
\hline & $\begin{array}{l}\text { Review } \\
\text { readability }\end{array}$ & $\begin{array}{l}\text { The extent to which the text can be read } \\
\text { and understood by consumers (Klare 1974; } \\
\text { Smith and Taffler 1992) }\end{array}$ & $\begin{array}{l}\text { Automated Readability Index (ARI, a metric } \\
\text { to evaluate the readability of a language text) } \\
\text { (Korfiatis, García-Bariocanal, and Sánchez- } \\
\text { Alonso 2012) }\end{array}$ \\
\hline & $\begin{array}{l}\text { Review } \\
\text { length }\end{array}$ & $\begin{array}{l}\text { The elaborateness of the reviews (Liu and } \\
\text { Park 2015). }\end{array}$ & $\begin{array}{l}\text { The number of words in an online review (Liu } \\
\text { and Park 2015) }\end{array}$ \\
\hline
\end{tabular}




\begin{tabular}{|c|c|c|}
\hline $\begin{array}{l}\text { Control } \\
\text { variables }\end{array}$ & ID hotel & $\begin{array}{l}\text { Dummy variables that refer to the } \\
\text { identification number of the hotel the online } \\
\text { review refers to. } \\
\text { Dummy variables that refer to the year when } \\
\text { the review was posted. }\end{array}$ \\
\hline
\end{tabular}

Note: n.a. stands for not applicable.

Table 2

Descriptive statistics.

\begin{tabular}{lllll}
\hline Variable & Minimum & Maximum & Mean & Standard deviation \\
\hline Dependent variable & & & & \\
\hline Review helpfulness & 0 & 48 & 0.883 & 1.834 \\
\hline Independent variable & & & & \\
\hline Extreme negative rating & 0 & 1 & 0.038 & 0.192 \\
\hline Moderator variables & & & & \\
\hline Reviewer identity disclosure & 0 & 1 & 0.847 & 0.360 \\
Reviewer expertise & 0 & 6,539 & 21.309 & 66.999 \\
Review readability & -1.131 & $3,568.09$ & 21.607 & 86.995 \\
Review length & 1 & 1,590 & 79.798 & 81.202 \\
\hline Control variable & & & & \\
\hline ID hotel & 1 & 220 & & \\
Year & 2013 & 2015 & & \\
\hline
\end{tabular}

\section{Table 3}

VIF and tolerance level values.

\begin{tabular}{lll}
\hline Variable & VIF & Tolerance \\
\hline Extreme negative rating & 1.014 & 0.986 \\
Reviewer identity disclosure & 1.000 & 0.999 \\
Reviewer expertise & 1.009 & 0.990 \\
Review readability & 1.031 & 0.969 \\
Review length & 1.582 & 0.631 \\
ID hotel & 1.540 & 0.649 \\
Year & 1.009 & 0.991 \\
\hline
\end{tabular}

Table 4 
Tobit regression models. Dependent variable: Online review helpfulness.

\begin{tabular}{|c|c|c|c|c|c|}
\hline \multirow[t]{2}{*}{ Model } & \multirow[t]{2}{*}{ Hp } & \multicolumn{2}{|c|}{ M1 } & \multicolumn{2}{|c|}{ M2 } \\
\hline & & Coeff. & Std. err. & Coeff. & Std. err. \\
\hline \multicolumn{6}{|l|}{ First order effects } \\
\hline Extreme negative rating (ENR) & H1 & $0.117 * * *$ & 0.008 & $0.088 * * *$ & 0.017 \\
\hline Reviewer identity disclosure (RID) & & & & 0.007 & 0.015 \\
\hline Reviewer expertise (RE) & & & & $0.093 * * *$ & 0.006 \\
\hline Review readability (RR) & & & & 0.005 & 0.007 \\
\hline Review length (RL) & & & & $0.068 * * *$ & 0.017 \\
\hline \multicolumn{6}{|l|}{ Second order effects } \\
\hline ENR x RID & $\mathrm{H} 2$ & & & $0.034 *$ & 0.017 \\
\hline ENR x RE & H3 & & & $0.032 * * *$ & 0.007 \\
\hline ENR $x$ RR & $\mathrm{H} 4$ & & & $0.019 * *$ & 0.006 \\
\hline ENR x RL & H5 & & & $0.023 * * *$ & 0.007 \\
\hline \multicolumn{6}{|l|}{ Control variables } \\
\hline ID hotel & & Included & Included & Included & Included \\
\hline Year & & Included & Included & Included & Included \\
\hline Constant & & $0.515 * * *$ & 0.116 & $0.529 * * *$ & 0.115 \\
\hline LR Chi-Squared & & \multicolumn{2}{|c|}{$2,752.43 * * *$} & \multicolumn{2}{|c|}{$3,026.71 * * *$} \\
\hline Pseudo R Squared & & \multicolumn{2}{|c|}{$20.89 \%$} & \multicolumn{2}{|c|}{$22.98 \%$} \\
\hline
\end{tabular}

Note: ${ }^{* *}$ p-value $<0.001 ; * * p<0.01 ; * p<0.05$; control variables are omitted in the table and are available upon request.
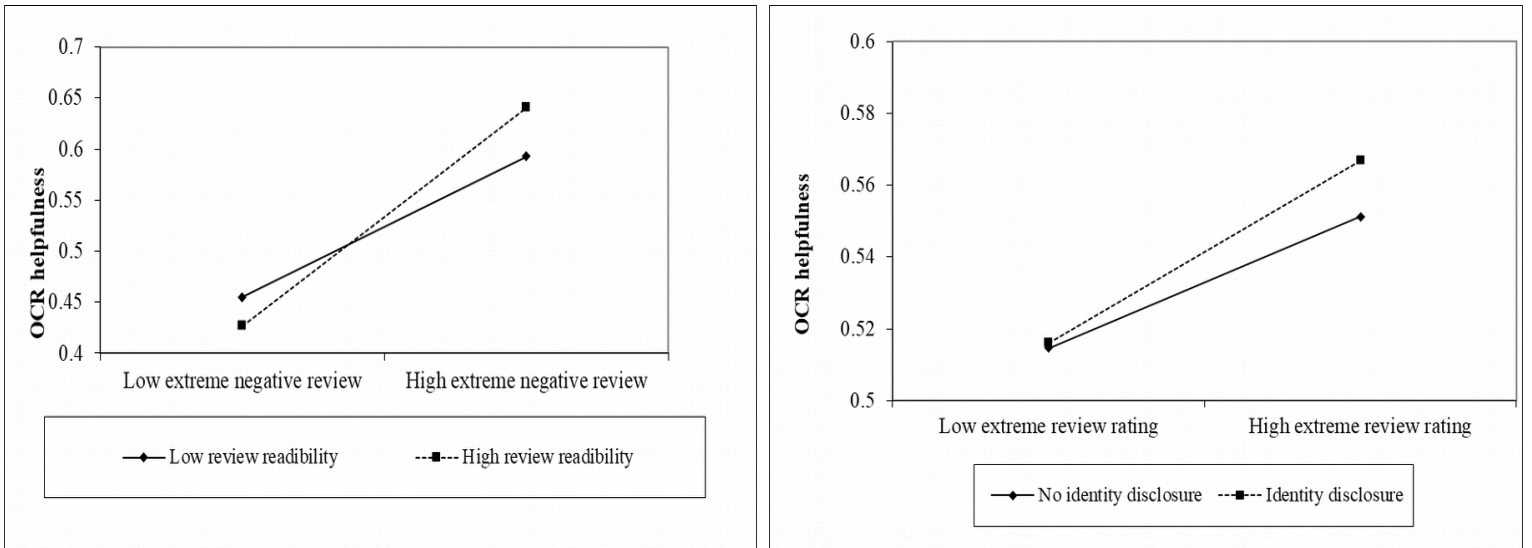

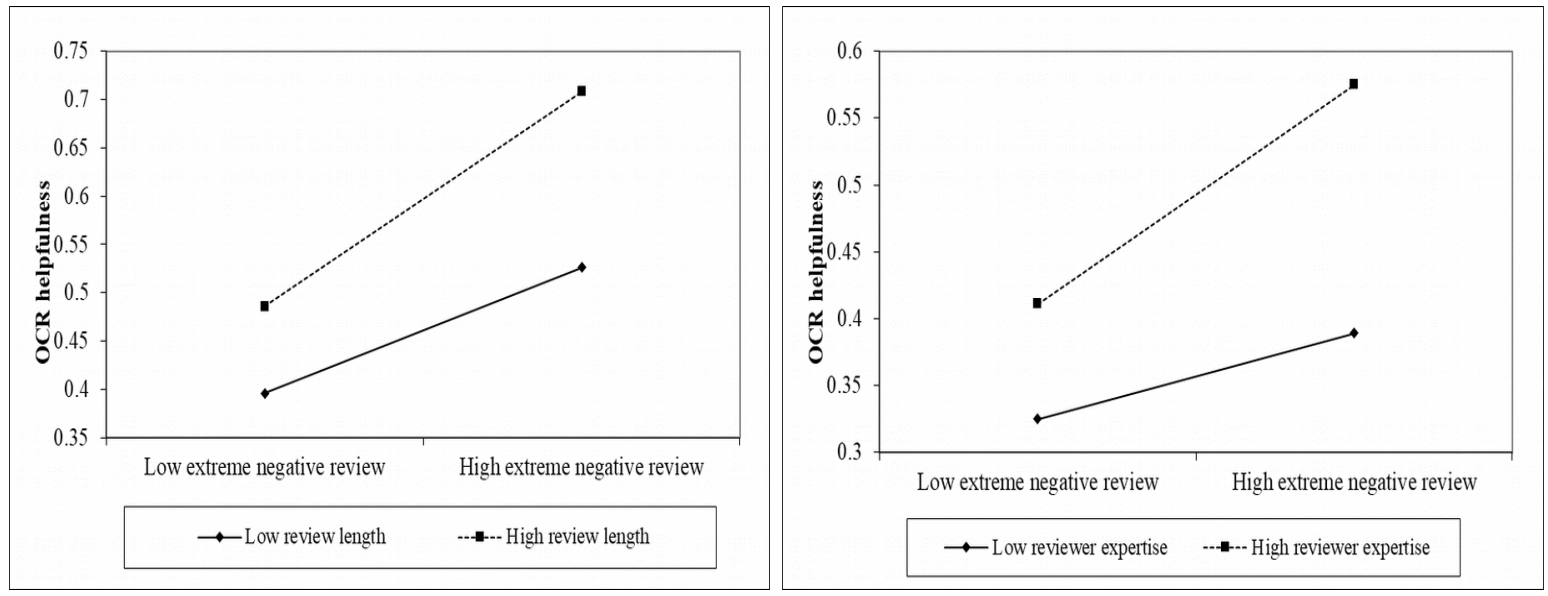

Figure 2. Graphical representation of the significant moderating effects.

\section{Table 5}

Hypotheses testing summary.

\begin{tabular}{lc}
\hline Hypotheses & Supported? \\
\hline H1: Extremely negative reviews will have a positive impact on review helpfulness. & Yes \\
H2: Extremely negative reviews will be perceived as more helpful when the reviewer discloses his identity. & Yes \\
H3: Extremely negative reviews will be perceived as helpful when the reviewer is expert. & Yes \\
H4: Extremely negative reviews will be perceived as helpful when the reviewer is readable. & Yes \\
H5: Extremely negative reviews will be perceived as helpful when the reviewer is long. & Yes \\
\hline
\end{tabular}

